\title{
Diagnostic value of the UCA1 test for bladder cancer detection: a clinical study
}

\author{
Dina Milowich ${ }^{1,2}$, Marie Le Mercier ${ }^{1}$, Nancy De Neve ${ }^{1}$, Flavienne Sandras ${ }^{1}$, Thierry Roumeguere ${ }^{3}$, \\ Christine Decaestecker ${ }^{4,5}$, Isabelle Salmon ${ }^{1,5}$ and Sandrine Rorive ${ }^{1,5^{*}}$
}

\begin{abstract}
Purpose: To evaluate the efficiency of the UCA1 test as a diagnostic tool for the detection of bladder cancer.

Methods: Between October 2009 and December 2011 the UCA1 test was performed on collected urine samples from 162 patients divided into screening and follow-up groups, based on the absence or presence of prior bladder cancer. The test performance was then evaluated in each group and compared to cystoscopy and urinary cytology.

Results: The overall sensitivity, specificity and positive and negative predictive values for the UCA1 test were 70, 70.7, 75.6 and $64.5 \%$, respectively. We observed no difference in performance for tumours of higher grade or stage, but sensitivity was increased in the screening population compared to patients under follow-up (83.9 vs. 59\%). The UCA1 test successfully detected all 7 cases of isolated carcinoma in situ and was more sensitive in this particular setting than cystoscopy or urinary cytology.

Conclusion: The efficiency of the UCA1 test for the detection of primary and recurring bladder cancer in our study was lower than previously reported. We confirmed the role of UCA1 as a possible adjunct to cystoscopy and cytology when a primary bladder cancer is suspected, but its role in the follow-up of recurring tumours remains limited. Further studies are needed to investigate the role of the UCA1 test in the early detection of carcinoma in situ lesions.
\end{abstract}

Keywords: UCA1 RNA, human, Urothelial carcinoma associated 1, Bladder cancer, Biomarker, Urinary marker

\section{Background}

Bladder cancer $(\mathrm{BC})$ is the second most common urologic cancer. Although the majority of cases are diagnosed at early stages, up to $50 \%$ of tumours recur and $15-40 \%$ grow into muscle invasive disease (Amin et al. 2015). According to current guidelines, the diagnostic standard for BC is cystoscopy, often combined with urinary cytology (Kamat et al. 2013). This is also the approach used to follow-up patients with a history of BC. Though photodynamic diagnosis has improved the sensitivity of white cystoscopy for carcinoma in situ (CIS) lesions, both procedures remain invasive, time-consuming and costly, therefore making $\mathrm{BC}$ one of the most expensive malignancies to monitor and treat (Isfoss 2011; Van Rhijn et al. 2009). Cytology is a non-invasive test often performed on

\footnotetext{
*Correspondence: sandrine.rorive@erasme.ulb.ac.be

${ }^{1}$ Department of Pathology, Erasme University Hospital, Université Libre

de Bruxelles, 808 Route de Lennik, 1070 Brussels, Belgium

Full list of author information is available at the end of the article
}

voided urine, with high specificity (96\%) but low sensitivity (44\%), particularly for low-grade tumours (Kamat et al. 2013). Several urine markers have been studied to help diagnose $\mathrm{BC}$, and thereby decrease the need for cystoscopy as well as make following-up bladder cancer patients more cost-effective. To date, the Food and Drug Administration has approved six urine biomarkers for BC detection (Kamat et al. 2013; Tilki et al. 2011). Most markers have shown better sensitivity compared to cytology; however, their specificity remains lower (Tilki et al. 2011). None of those markers are currently recommended as standard diagnostic tools in routine urology (Kamat et al. 2013; Tilki et al. 2011).

Urothelial carcinoma associated 1 (UCA1) was recently identified as a non-coding RNA upregulated in $\mathrm{BC}$ compared to normal bladder tissues, and is thought to be involved in embryogenesis and in $\mathrm{BC}$ progression (Wang et al. 2006, 2008, 2012). Overexpression of UCA1 in the BLS-211 BC cell line significantly enhanced the

\section{黛 Springer}

(c) 2015 Milowich et al. This article is distributed under the terms of the Creative Commons Attribution 4.0 International License (http://creativecommons.org/licenses/by/4.0/, which permits unrestricted use, distribution, and reproduction in any medium, provided you give appropriate credit to the original author(s) and the source, provide a link to the Creative Commons license, and indicate if changes were made. 
tumorigenicity, invasion potential and drug resistance, both in vitro and in vivo (Wang et al. 2008). Yang et al. showed that UCA1 stimulates cell proliferation via the p300 coactivator CREB, through a PI3K-AKT dependent pathway (Yang et al. 2012). UCA1 was also identified as a very sensitive and specific urine marker of BC (Wang et al. 2006; Zhang et al. 2012; Srivastava et al. 2014). A recent study yielded a sensitivity of $79.49 \%$ and a specificity of $79.73 \%$, suggesting that the $U C A 1$ test could be used as an adjunct to cytology in early diagnosis of primary urinary BC (Srivastava et al. 2014). Those promising results motivated us to study the $U C A 1$ test in an independent cohort, with a view to validating $U C A 1$ as a reliable biomarker for $\mathrm{BC}$ detection. Instead of using fresh urine samples stored on ice, as previously described, we developed the $U C A 1$ test on fixed urine samples in order to facilitate its use in daily practice (Wang et al. 2006). The test has been accredited (BELAC, ISO15189) since September 2009. The present work aims to report our experience regarding the clinical value of the $U C A 1$ test when compared to routine diagnostic methods.

\section{Methods}

\section{Patient selection}

Freshly voided urine samples were obtained from 162 patients between October 2009 and December 2012 at Erasme University Hospital, after approval by the local Ethical Committee (Ref: P2010/338). Patients were included in the study if they were (1) evaluated for suspected primary $B C$, (2) under surveillance for $B C$ or (3) followed for other urological conditions. The clinical data collected for each patient include age, prior medical history and treatment, symptoms, cystoscopic and/ or imaging findings, and follow-up through August 2014 (Table 1). All BC diagnoses were confirmed by histology, except for one patient. This person's histological confirmation was forgone due to advanced age, despite a visible bladder tumour at both cystoscopy and CT scan, as well as malignant urothelial cells identified by cytology. White cystoscopy was performed for all patients and regarded as positive in cases involving apparent papillary or flat lesions and considered negative if findings were normal.

\section{Urine and tissue samples}

Urine samples were collected in a tube containing $25 \mathrm{ml}$ of the fixative solution Saccomanno ${ }^{\text {тм }}$ (Prosan, Merelbeke, Belgium) and were delivered to the laboratory within $24 \mathrm{~h}$. From these samples, $50 \mathrm{ml}$ was used to conduct routine cytology. All cytological diagnoses were reviewed by a uropathologist (SR). Cytology was categorized as positive if cancer cells or cells with atypical changes suggesting malignancy were found, and as negative if normal cells or cells with inflammatory atypical changes were found.
Table 1 Patients demographics and baseline features

\begin{tabular}{|c|c|c|c|c|c|}
\hline \multirow[t]{2}{*}{$\begin{array}{l}\text { Overall patients } \\
(n=161)\end{array}$} & \multicolumn{2}{|c|}{$\begin{array}{l}\text { Screening } \\
\text { group }\end{array}$} & \multicolumn{2}{|c|}{$\begin{array}{l}\text { Follow-up } \\
\text { group }\end{array}$} & \multirow[t]{2}{*}{$p$ value } \\
\hline & \multicolumn{2}{|c|}{$\mathrm{n}=79$} & \multicolumn{2}{|c|}{$\mathrm{n}=83$} & \\
\hline \multicolumn{6}{|l|}{ Clinical features $^{a}$} \\
\hline Age (median (range)) & \multicolumn{2}{|c|}{$68(32-90)$} & \multicolumn{2}{|c|}{$70(35-90)$} & \\
\hline Hematuria & 48 & $60.8 \%$ & 5 & $6 \%$ & $p<0.00001$ \\
\hline Urinary tract infection & 8 & $10.1 \%$ & 1 & $1.2 \%$ & $p=0.01$ \\
\hline $\begin{array}{l}\text { Benign prostatic } \\
\text { hyperplasia }\end{array}$ & 18 & $22.8 \%$ & 6 & $7.2 \%$ & $p=0.004$ \\
\hline Renal transplant & 10 & $12.7 \%$ & 5 & $6 \%$ & $p=0.1$ \\
\hline Lithiasis & 5 & $6.3 \%$ & 1 & $1.2 \%$ & $p=0.09$ \\
\hline Hydronephrosis & 7 & $8.9 \%$ & 2 & $2.4 \%$ & $p=0.07$ \\
\hline LUTS & 12 & $15.2 \%$ & 1 & $1.2 \%$ & $p=0.0009$ \\
\hline Schistozomiasis & 2 & $2.5 \%$ & 0 & $0 \%$ & $p=0.24$ \\
\hline $\begin{array}{c}\text { Aristocholic acid } \\
\text { nephropathy }\end{array}$ & 5 & $6.3 \%$ & 5 & $6 \%$ & $p=1$ \\
\hline Other malignancies & 14 & $17.7 \%$ & 15 & $18.1 \%$ & $p=1$ \\
\hline UCA1 test & & & & & $p=0.04$ \\
\hline Positive & 43 & $54.4 \%$ & 33 & $39.8 \%$ & \\
\hline Negative & 36 & $45.6 \%$ & 50 & $60.2 \%$ & \\
\hline Cytology & & & & & $p=0.09$ \\
\hline Positive & 21 & $26.6 \%$ & 14 & $16.9 \%$ & \\
\hline Negative & 49 & $62 \%$ & 59 & $71.1 \%$ & \\
\hline Unsatisfactory & 9 & $11.4 \%$ & 10 & $12 \%$ & \\
\hline Cystoscopy & & & & & $p=0.56$ \\
\hline Positive & 31 & $39.2 \%$ & 36 & $43.4 \%$ & \\
\hline Negative & 39 & $49.4 \%$ & 45 & $54.2 \%$ & \\
\hline Not performed & 9 & $11.4 \%$ & 2 & $2.4 \%$ & \\
\hline Histology & & & & & $p=0.56$ \\
\hline Benign & 12 & $15.2 \%$ & 15 & $18.1 \%$ & \\
\hline Malignant & 30 & $38 \%$ & 39 & $47 \%$ & \\
\hline $\begin{array}{l}\text { Urothelial } \\
\text { carcinoma }\end{array}$ & 27 & & 38 & & \\
\hline $\begin{array}{l}\text { Squamous } \\
\text { carcinoma }\end{array}$ & 2 & & 0 & & \\
\hline Adenocarcinoma & 0 & & 1 & & \\
\hline Small cell carcinoma & 1 & & 0 & & \\
\hline Not performed & 37 & $46.8 \%$ & 29 & $34.9 \%$ & \\
\hline Stage & & & & & \\
\hline pTis & 1 & $1.3 \%$ & 6 & $7.2 \%$ & \\
\hline pTa & 6 & $7.6 \%$ & 15 & $18 \%$ & \\
\hline pT1 & 9 & $11.8 \%$ & 6 & $7.2 \%$ & \\
\hline pT2 & 9 & $11.8 \%$ & 8 & $9.6 \%$ & \\
\hline pT3 & 4 & $5.1 \%$ & 1 & $1.2 \%$ & \\
\hline pT4 & 1 & $1.3 \%$ & 3 & $3.6 \%$ & \\
\hline Grade & & & & & \\
\hline PUNLMP & - & & - & & \\
\hline Low grade & 7 & $8.9 \%$ & 16 & $19.3 \%$ & \\
\hline High grade & 19 & $24 \%$ & 16 & $19.3 \%$ & \\
\hline $\mathrm{CIS}$ & 1 & $1.3 \%$ & 6 & $7.2 \%$ & \\
\hline Not available & 3 & $3.8 \%$ & - & & \\
\hline
\end{tabular}


Table 1 continued

\begin{tabular}{llllll}
\hline $\begin{array}{l}\text { Overall patients } \\
(\mathbf{n = 1 6 1 )}\end{array}$ & $\begin{array}{l}\text { Screening } \\
\text { group }\end{array}$ & & $\begin{array}{l}\text { Follow-up } \\
\text { group }\end{array}$ & p value \\
$\begin{array}{c}\text { Multicentricity } \\
\text { Single tumours }\end{array}$ & 16 & $20.2 \%$ & 20 & $24.1 \%$ \\
$\quad$ Multiple tumours & 10 & $12.6 \%$ & 11 & $13.6 \%$ \\
$\quad$ Not available & 4 & $5.1 \%$ & 1 & $1.2 \%$ \\
\hline
\end{tabular}

a Some patients present multiple clinical features.

The remaining urine volume was centrifuged at 3,000 rpm for $30 \mathrm{~min}$ and rinsed with PBS. The resulting pellets were suspended in RNAlater $^{\mathrm{Tm}}$ solution (Qiagen, Venlo, Netherlands) and stored at $4^{\circ} \mathrm{C}$. RNA extraction was conducted using an RNeasy Mini kit (Qiagen) following the manufacturer's recommendations. After checking the RNA quality and purity (NanoDrop 2000, Thermo Scientific, Aalst, Belgium), 50 ng of RNA extracts were submitted to reverse transcription using the Sensiscript Reverse Transcription Kit (Qiagen) and oligo(dT) primers (Invitrogen, Gent, Belgium). Amplification was performed using $U C A 1$ specific primers (Forward: 5'-GGGACTCCTTCGTGAGACC-3' and Reverse: 5'-AGAGGAACGGATGAAGCCTG-3'). The Tata box binding protein $(T B P)$ was used as a housekeeping gene (Forward: 5'-GGCACCACTCCACTGTATC-3' and Reverse: $5^{\prime}$-AATCAGTGCCGTGGTTCGT-3'). For both PCR reactions, 40 cycles were run (Thermocycler $\mathrm{T} 3$, $94^{\circ} \mathrm{C}$ for $45 \mathrm{~s}, 57^{\circ} \mathrm{C}$ for $1 \mathrm{~min}, 72^{\circ} \mathrm{C}$ for $30 \mathrm{~s}$ ). The PCR product was then resolved on agarose gels. Satisfactory tests were categorized using a three-tier score (negative, low or high $U C A 1$ gene expression). The test was considered positive if the $U C A 1$ gene was highly expressed, and negative if the $U C A 1$ gene was weakly or not expressed at all in the sample analysed (Figure 1). Two independent investigators (MLM and SR), blinded to the clinical data, cystoscopy findings and cytological diagnoses, evaluated the result of each $U C A 1$ test.

In 96 patients, tissue samples were retrieved by biopsy, transurethral resection of the bladder (TURB) or surgical procedures. The histopathological diagnoses were reviewed by a uropathologist (SR).

\section{Data analysis}

Patients were divided into screening and follow-up groups, based on absence or presence of prior BC. Patients were considered disease-free if the workup was negative and no evidence of $\mathrm{BC}$ was found in the six following months. Patients with insufficient follow-up were excluded from the study. We evaluated the sensitivity, specificity, positive and negative predictive values of the

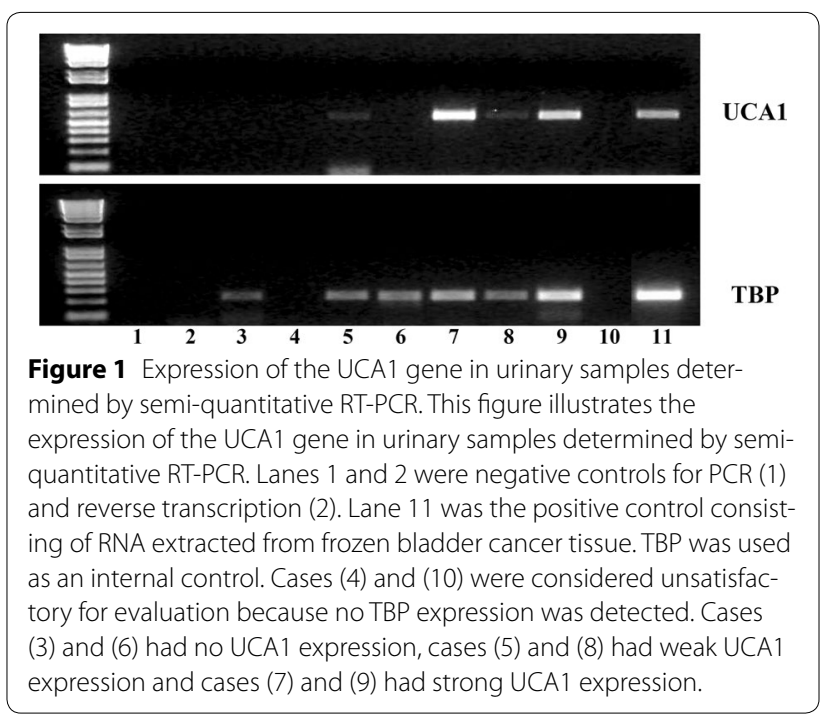

UCA1 test in both patient groups compared to cystoscopy and cytology.

\section{Results}

Among the 162 patients included in this study, 79 had no prior history of $\mathrm{BC}$ and 83 were part of the followup cohort. For each of these two groups, the breakdown between patients in terms of clinical features, cytology, cystoscopy and UCA1 test results is shown in Table 1. In all, 69 diagnoses of $\mathrm{BC}$ were made, of which 30 were primary BCs and 39 recurrent cases. Most cases $(n=65)$ were diagnosed as urothelial carcinomas, though two cases of pure squamous cell carcinoma and single cases of primary bladder adenocarcinoma and small cell carcinoma were also encountered. For 66 patients, no histological material was available and 65 of these patients were considered disease-free, as there was no suspicion of malignancy at the initial workup or during a follow-up of at least 6 months either. One patient was diagnosed with a locally advanced bladder tumour on imaging findings and malignant urothelial cells were identified by cytology, but no further investigations were carried out due to the patient's age and performance status.

Table 2 illustrates the sensitivities, specificities, positive and negative predictive values of urinary cytology, cystoscopy and the $U C A 1$ test designed to detect $\mathrm{BC}$ in the screening and follow-up groups.

The overall sensitivities of cytology, cystoscopy and the $U C A 1$ test were $50.8,79.1$ and $70 \%$. The sensitivity of the UCA1 test was higher in the screening group compared to the follow-up group, (83.9 vs. 59\%), yielding a negative predictive value of 86.1 and 68\% respectively. Cystoscopy and urinary cytology were also less sensitive for detecting recurrences, with cystoscopy remaining the most 
Table 2 Sensitivity of diagnostic methods for bladder cancer (including carcinoma in situ) according to grade and stage

\begin{tabular}{|c|c|c|c|c|c|c|c|}
\hline \multirow[b]{2}{*}{ Overall } & \multirow[b]{2}{*}{$n=69$} & \multicolumn{2}{|c|}{ UCA1 test } & \multicolumn{2}{|c|}{ Cytology } & \multicolumn{2}{|c|}{ Cystoscopy } \\
\hline & & & & & & & \\
\hline Urothelial carcinoma & $n=65$ & $46 / 65$ & $70.8 \%$ & $29 / 58^{a}$ & $50 \%$ & $51 / 63^{d}$ & $81 \%$ \\
\hline Low-grade & $n=23$ & $14 / 23$ & $60.9 \%$ & $2 / 17$ & $11.8 \%$ & $19 / 23$ & $82.6 \%$ \\
\hline High-grade & $n=35$ & $25 / 35$ & $71.4 \%$ & $24 / 34$ & $70.6 \%$ & $29 / 34$ & $85.3 \%$ \\
\hline $\mathrm{CIS}$ & $n=7$ & $7 / 7$ & $100 \%$ & $3 / 7$ & $42.9 \%$ & $3 / 6$ & $50 \%$ \\
\hline Squamous cell carcinoma & $n=2$ & $1 / 2$ & & $1 / 2$ & & $1 / 2$ & \\
\hline Adenocarcinoma & $n=1$ & $0 / 1$ & & $0 / 1$ & & $0 / 1$ & \\
\hline Small cell carcinoma & $n=1$ & $1 / 1$ & & $1 / 1$ & & $1 / 1$ & \\
\hline pTa & $n=21$ & $12 / 21$ & $57.1 \%$ & $2 / 15^{b}$ & $13.3 \%$ & $18 / 21$ & $85.7 \%$ \\
\hline pT1 & $n=15$ & $14 / 15$ & $93.3 \%$ & $9 / 15$ & $60 \%$ & $13 / 15$ & $86.7 \%$ \\
\hline$\geq \mathrm{pT} 2$ & $n=26$ & $15 / 26$ & $57.7 \%$ & $17 / 25^{c}$ & $68 \%$ & $19 / 25^{e}$ & $76 \%$ \\
\hline
\end{tabular}

a 7 cases were unsatisfactory for interpretation ( 6 low grade and 1 high grade tumors); ${ }^{\mathrm{b}} 6$ cases were unsatisfactory for interpretation; ${ }^{\mathrm{c}} 1$ case was unsatisfactory for interpretation; ${ }^{d}$ cystoscopy was not performed in 2 cases (1 high grade tumors and 1 CIS); ${ }^{e}$ cystoscopy was not performed in 1 case.

Table 3 Diagnostic value of the UCA1 test, urinary cytology and cystoscopy for the detection of bladder cancer

\begin{tabular}{llll}
\hline & UCA1 test & Cytology & Cystoscopy \\
\hline Screening & & & \\
Sensitivity & $83.9 \%$ & $71.4 \%$ & $90 \%$ \\
Specificity & $64.6 \%$ & $97.6 \%$ & $90 \%$ \\
Negative predictive value & $86.1 \%$ & $83.7 \%$ & $92.3 \%$ \\
Positive predictive value & $60.5 \%$ & $95.2 \%$ & 87.1 \\
Follow-up & & & \\
Sensitivity & $59 \%$ & $34.3 \%$ & $70.3 \%$ \\
Specificity & $77.3 \%$ & $94.7 \%$ & $77.3 \%$ \\
Negative predictive value & $68 \%$ & $61 \%$ & $75.6 \%$ \\
Positive predictive value & $69.7 \%$ & $85.7 \%$ & $72.2 \%$ \\
Overall & & & \\
Sensitivity & $70 \%$ & $50.8 \%$ & $79.1 \%$ \\
Specificity & $70.7 \%$ & $96.3 \%$ & $83.3 \%$ \\
Negative predictive value & $75.6 \%$ & $71.3 \%$ & $83.3 \%$ \\
Positive predictive value & $64.5 \%$ & $91.4 \%$ & $79.1 \%$ \\
\hline
\end{tabular}

efficient procedure (90 and $70.3 \%$ sensitivity for screening and follow-up), while urinary cytology detected $71.4 \%$ of primary BCs and only $34.3 \%$ of recurrences. Conversely, the $U C A 1$ test proved to be more specific in the followup group as compared to the screening group (77.3 vs. $64.6 \%$ ), yielding a positive predictive value of $64.5 \%$ overall. The specificity of cystoscopy in the follow-up group was equivalent $(77.3 \%)$ to the $U C A 1$ test, but both cystoscopy and cytology were more specific than the UCA1 test in the screening setting.

Table 3 illustrates the number and percentages of patients reported as positive by cytology, cystoscopy and the UCA1 test according to grade and stage. Cytology was more often positive in $\mathrm{BC}$ of higher grade $(70.6 \%$ in high-grade vs. $11.8 \%$ in low-grade tumours) and stage (13.3\% for $\mathrm{pTa}, 60 \%$ for $\mathrm{pT} 1$ and $71.4 \%$ for $\geq \mathrm{pT} 2$ tumours). Conversely, the result of the $U C A 1$ test did not vary significantly between low-grade and high-grade tumours (60.9 vs. $71.4 \%)$ and did not correlate with stage $(57.1 \%$ for pTa tumours vs. $93.3 \%$ for pT1 tumours; $59.1 \%$ for $\geq$ pT2 tumours). Cystoscopy remained the most efficient diagnostic tool, irrespective of grade and stage, except for CIS. Interestingly, the $U C A 1$ test successfully detected all seven cases of CIS and was more sensitive than cytology or cystoscopy in this setting. The $U C A 1$ test was also positive in one of two cases of squamous cell carcinoma and small cell carcinoma; however, the only case of primary bladder adenocarcinoma did not express $U C A 1$.

\section{Discussion}

Since its first description in 2006, several studies have confirmed UCA1 to be a biomarker for urothelial carcinoma and studied its expression in other cancers, including colorectal and breast cancers (Wang et al. 2006, 2008, 2012; Yang et al. 2012; Zhang et al. 2012; Srivastava et al. 2014; Han et al. 2014; Huang et al. 2014). Moreover, long non-coding RNAs, like $U C A 1$, are increasingly thought to play a pivotal role in cancer development and progression (Shi et al. 2013; Li and Chen 2013). To date, only three studies have addressed the role of UCA1 as a urinary marker. $\mathrm{BC}$ is the second most common urologic malignancy, yet it is one of the most challenging to treat due to significant tumour heterogeneity and potential life-long follow-up, which includes time-consuming and invasive procedures. The implementation of a urinary biomarker in clinical practice could allow for longer intervals between cystoscopies and a less invasive follow-up, but should not come at the expense of lower sensitivity. 
In previous studies, the sensitivity of the UCA1 marker ranged from 79.5 to $88.5 \%$. With an overall sensitivity of $70 \%$, the ability of the $U C A 1$ test to detect $\mathrm{BC}$ was significantly lower in our series. However, when limited to the screening group, the $U C A 1$ test yielded a sensitivity of $83.9 \%$, which is comparable to reported results. Two of the previous studies did not detail the patients' history of $\mathrm{BC}$, but Srivastava et al. reported a significant difference in expression of $U C A 1$ in recurrent tumours compared to primary tumours ( $\mathrm{p}<0.001$ ), emphasizing the necessity to analyse patients with recurrent BC separately when evaluating a novel biomarker (Srivastava et al. 2014). The positive and negative predictive values of the $U C A 1$ test were lower than previously reported (64.5 and $75.6 \%$ respectively), despite a relatively high prevalence of bladder cancer in our patients population (Srivastava et al. 2014).

The overall specificity of the $U C A 1$ test was $70.7 \%$, ranging lower than the previously published results (79.7-92.3\%). In our study, 27 patients with a positive $U C A 1$ test had no evidence of disease for at least 6 months and up to 53 months of follow-up. Nevertheless, late recurrences have been reported, which provide reasonable explanations for false positive results with other urinary markers, particularly FISH-based markers (Kamat et al. 2014 Oct). Anticipatory false-positive findings cannot be excluded at this stage and overexpression of $U C A 1$ may be due to its expression in early precursor lesions that remain clinically undetectable. This hypothesis is supported by the detection of UCA1 in all seven cases of CIS and, additionally, in two cases of urothelial dysplasia (data not shown). Though four patients with false-positive tests were under surveillance for $\mathrm{BC}$ due to exposure to aristocholic acid, and one patient had been diagnosed with chronic schistosomiasis-two conditions associated with urothelial carcinogenic ability and urothelial dysplasia -, we did not find any association between particular clinical features and a false-positive test (Botelho et al. 2011; Lemy et al. 2008). Our study included only seven patients with CIS, but it is interesting to note that the UCA1 test detected three additional cases compared to cystoscopy. However, in order to evaluate the efficiency of the $U C A 1$ test in flat urothelial lesions, further studies on larger cohorts are necessary.

Contrary to previous reports where $U C A 1$ has emerged as a particularly sensitive marker for superficial highgrade tumours, we did not find any significant difference in terms of sensitivity when the UCA1 test was analysed according to grade. Although the $U C A 1$ test was particularly efficient in detecting pT1 tumours, the sensitivity for both non-invasive and muscle-invasive tumours was $57 \%$.

$U C A 1$ expression was increased in various urothelial neoplastic lesions, including urothelial dysplasia, CIS and papillary low-grade and high-grade urothelial carcinomas-each associated with different morphology, pathogenesis and prognostic implications. Increased expression of $U C A 1$ has been associated with tumour proliferation, migration and invasion, though the exact mechanisms are yet to be elucidated. Recently, Wang et al. reported that $U C A 1$ promotes cell growth by downregulating the cell cycle inhibitor p21 via BRG1, a chromatin remodelling factor with anti-tumour properties (Wang et al. 2014). Furthermore, upregulated $U C A 1$ has been shown to promote resistance to cisplatin-based chemotherapy in bladder cancer cells (Fan et al. 2014). Taken together, these findings indicate that $U C A 1$ plays an important role in $\mathrm{BC}$ pathogenesis and progression, while its characterisation may provide new insights in early stages of BC development and, possibly, even new prognostic factors and therapeutic targets. It remains to be proven whether $U C A 1$ is a suitable diagnostic urinary biomarker in $\mathrm{BC}$ and a useful contribution to already existing diagnostic procedures in daily urologic practice.

In conclusion, the efficiency of the UCA1 test for the diagnosis of $\mathrm{BC}$ in our study was lower than previously reported. Our results highlight the importance of testing novel urinary biomarkers in specific patient populations. The $U C A 1$ test cannot replace cystoscopy for the evaluation of patients with suspected primary BC or in the context of a follow-up for bladder cancer. While it may aid in the detection of CIS, more extensive studies are needed to confirm these findings. Conversely, our results did not provide evidence that the $U C A 1$ test is suitable for the follow-up of patients with previous $B C$, due to its low sensitivity in this population.

\section{End note}

The present study has been approved by the Ethical Committee of the Erasme University Hospital (Ref: P2010/338).

\section{Authors' contributions}

DM data collection, data analysis, manuscript writing. MLM project development, data analysis and manuscript writing/editing. NDN project development, data analysis. FS project development. TR manuscript editing. CD data analysis. IS project development. SR project development, data analysis and manuscript writing/editing. All authors read and approved the final manuscript.

\section{Author details}

1 Department of Pathology, Erasme University Hospital, Université Libre de Bruxelles, 808 Route de Lennik, 1070 Brussels, Belgium. ${ }^{2}$ Department of Pathology, Jules Bordet Institute, Université Libre de Bruxelles, Brussels, Belgium. ${ }^{3}$ Department of Urology, Erasme University Hospital, Université Libre de Bruxelles, Brussels, Belgium. ${ }^{4}$ Laboratory of Image Synthesis and Analysis (LISA), Brussels School of Engineering/École Polytechnique de Bruxelles, Université Libre de Bruxelles, Brussels, Belgium. ${ }^{5}$ DIAPath, Center for Microscopy and Molecular Imaging (CMMI), Académie Universitaire Wallonie-Bruxelles, Gosselies, Belgium. 


\section{Acknowledgements}

This work has been carried out with the support of grants awarded by the "Fonds Yvonne Boël", Brussels, Belgium. The CMMI is supported by the European Regional Development. Fund and Wallonia. C.D. is a Senior Research Associate with the FNRS. C.D. is a Senior Research Associate with the "Fond National de la Recherche Scientifique", Brussels, Belgium.

\section{Compliance with ethical guidelines}

\section{Competing interests}

The authors declare that they have no competing interests.

Received: 24 April 2015 Accepted: 9 June 2015

Published online: 16 July 2015

\section{References}

Amin MB, Smith SC, Reuter VE, Epstein Jl, Grignon DJ, Hansel DE et al (2015) Update for the practicing pathologist: The International Consultation On Urologic Disease-European association of urology consultation on bladder cancer. Mod Pathol 28(5):612-630

Botelho MC, Oliveira PA, Lopes C, Correia da Costa JM, Machado JC (2011) Urothelial dysplasia and inflammation induced by Schistosoma haematobium total antigen instillation in mice normal urothelium. Urol Oncol 29:809-814

Fan Y, Shen B, Tan M, Mu X, Qin Y, Zhang F et al (2014) Long non-coding RNA UCA1 increases chemoresistance of bladder cancer cells by regulating Wnt signaling. FEBS J 281:1750-1758

Han Y, Yang Y, Yuan H, Zhang T, Sui H, Wei X et al (2014) UCA1, a long noncoding RNA up-regulated in colorectal cancer influences cell proliferation, apoptosis and cell cycle distribution. Pathology 46:396-401

Huang J, Zhou N, Watabe K, Lu Z, Wu F, Xu M et al (2014) Long non-coding RNA UCA1 promotes breast tumor growth by suppression of p27 (Kip1). Cell Death Dis 5:e1008

Isfoss BL (2011) The sensitivity of fluorescent-light cystoscopy for the detection of carcinoma in situ (CIS) of the bladder: a meta-analysis with comments on gold standard. BJU Int 108:1703-1707

Kamat AM, Hegarty PK, Gee JR, Clark PE, Svatek RS, Hegarty N et al (2013) ICUD-EAU International Consultation on Bladder Cancer 2012: screening, diagnosis, and molecular markers. Eur Urol 63:4-15
Kamat A, Vlahou A, Taylor J, Hudson ML, Pesch B, Ingersoll MA et al (2014) Considerations on the use of urine markers in the management of patients with high-grade non-muscle-invasive bladder cancer. Urol Oncol 32(7):1069-1077

Lemy A, Wissing KM, Rorive S et al (2008) Late onset of bladder urothelial carcinoma after kidney transplantation for end-stage aristolochic acid nephropathy: a case series with 15-year follow-up. Am J Kidney Dis 51:471-477

Li CH, Chen Y (2013) Targeting long non-coding RNAs in cancers: progress and prospects. Int J Biochem Cell Biol 45:1895-1910

Shi X, Sun M, Liu H, Yao Y, Song Y (2013) Long non-coding RNAs : a new frontier in the study of human diseases. Cancer Lett 339:159-166

Srivastava AK, Singh PK, Rath SK, Dalela D, Goel MM, Bhatt MLB (2014) Appraisal of diagnostic ability of UCA1 as a biomarker of carcinoma of the urinary bladder. Tumor Biol 35:11435-11442

Tilki D, Burger M, Dalbagni G, Grossman HB, Hakenberg OW, Palou J et al (2011) Urine markers for detection and surveillance of non-muscle-invasive bladder cancer. Eur Urol 60:484-492

Van Rhijn BWG, Burger M, Lotan Y, Solsona E, Stief CG, Sylvester RJ et al (2009) Recurrence and progression of disease in non-muscle-invasive bladder cancer: from epidemiology to treatment strategy. Eur Urol 56:430-442

Wang X-S, Zhang Z, Wang H-C, Cai JL, Xu QW, Li MQ et al (2006) Rapid identification of UCA1 as a very sensitive and specific unique marker for human bladder carcinoma. Clin Cancer Res 12:4851-4858

Wang F, Li X, Xie X, Zhao L, Chen W (2008) UCA1, a non-protein-coding RNA up-regulated in bladder carcinoma and embryo, influencing cell growth and promoting invasion. FEBS Lett 582:1919-1927

Wang Y, Chen W, Yang C, Wu W, Wu S, Qin X et al (2012) Long non-coding RNA UCA1a (CUDR) promotes proliferation and tumorigenesis of bladder cancer. Int J Oncol 41:276-284

Wang X, Gong Y, Jin B, Wu C, Yang J, Wang L et al. (2014) Long non-coding RNA urothelial carcinoma associated 1 induces cell replication by inhibiting BRG1 in 5637 cells. Oncol Rep 32(3):1281-1290

Yang C, Li X, Wang Y, Zhao L, Chen W (2012) Long non-coding RNA UCA1 regulated cell cycle distribution via CREB through PI3-K dependent pathway in bladder carcinoma cells. Gene 496:8-16

Zhang Z, Hao H, Zhang C, Yang X, He Q, Lin J (2012) Evaluation of novel gene UCA1 as a tumor biomarker for the detection of bladder cancer. Zhonghua yi xue za zhi 92:384-387

\section{Submit your manuscript to a SpringerOpen ${ }^{\circ}$ journal and benefit from:}

- Convenient online submission

- Rigorous peer review

- Immediate publication on acceptance

- Open access: articles freely available online

- High visibility within the field

- Retaining the copyright to your article

Submit your next manuscript at $\downarrow$ springeropen.com 